\title{
Why and how is compassion necessary to provide good quality healthcare?
}

\section{Marianna Fotaki*}

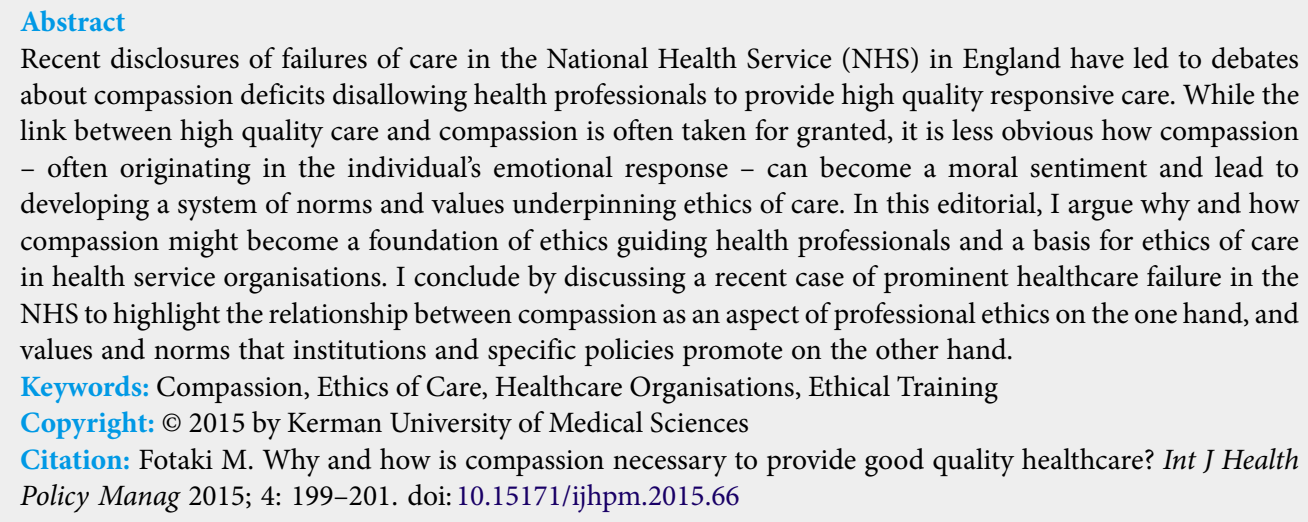
about compassion deficits disallowing health professionals to provide high quality responsive care. While the link between high quality care and compassion is often taken for granted, it is less obvious how compassion - often originating in the individual's emotional response - can become a moral sentiment and lead to developing a system of norms and values underpinning ethics of care. In this editorial, I argue why and how compassion might become a foundation of ethics guiding health professionals and a basis for ethics of care in health service organisations. I conclude by discussing a recent case of prominent healthcare failure in the NHS to highlight the relationship between compassion as an aspect of professional ethics on the one hand, and values and norms that institutions and specific policies promote on the other hand.

Keywords: Compassion, Ethics of Care, Healthcare Organisations, Ethical Training

Copyright: $\odot 2015$ by Kerman University of Medical Sciences

Citation: Fotaki M. Why and how is compassion necessary to provide good quality healthcare? Int $J$ Health Policy Manag 2015; 4: 199-201. doi: 10.15171/ijhpm.2015.66

\section{Article History:}

Received: 15 February 2015

Accepted: 13 March 2015

ePublished: 16 March 2015

\section{Introduction}

The issue of compassion in healthcare has been examined from a variety of perspectives including psychology, ethics, health education and policy (1-3). Prompted by the recent disclosures of failures of care in the National Health Service (NHS) in England (4,5), this debate has been centred on compassion as an individual attribute enabling health professionals to provide high quality responsive care. Several professional bodies are now actively working on developing guidelines in order to promote more patient-centred care. The role of compassion in health service delivery (6) is central to many of these deliberations.

Gilbert and Choden (7) define compassion as the "sensitivity to suffering in self and others with a commitment to try to alleviate and prevent it". Drawing on psychological literature their primary focus is on the motivation of individuals (8) but for healthcare professionals compassion is more about relational interpersonal practice (9). There is evidence that being cared for by compassionate clinicians increases and speeds up recovery (8). In addition, when clinicians feel themselves to be compassionately treated by their organisation and each other, they are more robust, creative and more open (6). The role of compassion in contemporary healthcare systems is increasingly important for both practice and policy: it is a social phenomenon that 'shapes and is shaped by conditions of inequality and coercion' (9) extending to the notions of social justice and solidarity (10).

While the link between high quality care and compassion is often taken for granted, it is less obvious how compassion often originating in the individual's emotional response - can become a moral sentiment and lead to developing a system of norms and values underpinning ethics of care (1). Furthermore, conflating compassion or other virtues such as empathy with being a good healthcare professional does not accurately reflect health service reality since care can mean either to feel a certain way or to carry out certain activities (11). While it undoubtedly contributes to a high quality therapeutic relationship $(12,13)$, responsive care cannot and should not be delivered by relying on health professionals' empathy and compassion only. Health policy objectives and organisational structures supporting them matter as much or even more sincesocial structures and context might either foster or impede it.

Below, I outline how compassion might become a foundation of ethics guiding health professionals and a basis for ethics of care in health services in organisations. I conclude by discussing a recent case of prominent healthcare failure in the NHS in England to highlight the relationship between compassion as an aspect of professional ethics on the one hand, and values and norms that institutions and specific policies promote on the other hand.

\section{Compassion as a foundation of ethics}

Philosophers' have taken diametrically different views on the role of compassion in ethics. Overall, there are conceptual issues and uncertainty over whether care and compassion can fit into ethics and moral philosophy (14). For Kant, ethics are rule-bound while all morality derives from essential dignity and the autonomy of rational human beings. Only morality based on rules and reason can lead to freedom, choice, discernment and decision-making based on reason (15). Schopenhauer - along with his philosophical hero David Hume - was one of the first Western philosophers to emphasise compassion as the basis of morality - thus rejecting Kant and the neo-Kantian tradition (16). MacIntyre in turn refuses the enlightenment philosophers' tendency (including Hume) to project their own morality as 'universal' sense of morals and a 
normative standard (17).

Yet the contribution of Kant to ethics of care in a healthcare context is important. The main novelty of his philosophy is as Ross explains (2008): 'his 'Copernican Revolution', that, as he puts it, is the representation that makes the object possible rather than the object that makes the representation possible' (15). The basis of Kant's morality where understanding of ethics has to do with perceiving (18) has potentially useful implications for inculcating compassion through health education: It suggests that as much as caring is an activity that can be learnt, perceiving the moral dimension of medical practice is also a skill that can be acquired to a greater or lesser extent (1).

Feminists raised their objections against philosophy articulated in terms of a male discourse and have argued for rethinking the whole male-dominated, principle-driven Western tradition in ethics (19) through the prism of care. Carol Gilligan's In a Different Voice offered the perspective that men and women have tendencies to view morality in different terms (20). The embodied ethical caring that women are more likely to follow has the potential to provide a more concrete ethical rules as compared to the abstract ethics of justice that is associated with male constructs $(19,20)$. More recently, Judith Butler, a feminist poststructuralist philosopher rehabilitated the role of affect further by focusing on the role of passionate attachments to social norms (21), which play a big role in healthcare arising from the material reality of ailing bodies. Such ethics of care in a healthcare context would denote a shift from dependency towards interdependency, offering an emancipatory perspective that defies the notion of passive acquiescence that is conventionally associated with being a patient (22). Last but not least, the psychosocial approaches in feminism stress the political importance of compassion that exceeds the sphere of individual intimacy (23). Only such an approach that acknowledges the interrelation between individual motivation and the social structure can serve as the foundation of compassion-based ethics of care proposed by political theorists (10). Trento thus argues for building caring institutions through a political process that considers the needs, contributions, and prospects of many different actors.

\section{Individual versus organisational ethics of care}

There is recognition of the role compassion plays in health professionals' individual morality (2) but it often appears to be in conflict with organisational logics and policies. As Poppke argues with reference to Lévinas: 'the question that arises is how can we live up to the demands of ethics and responsibility in a world held together by an array of impersonal organisations, institutions, and forms of discursive power?' (p. 505) (24).

Compassion that is a necessary basis for ethical foundation of care might arise from bodily affects and emotions but as an individual pre-moral sentiment on its own it cannot ensure responsive care. This is because sympathy-an emotionthat drives helping behaviour is all too often lacking in the situations where it is most warranted and, when aroused, is prone to direct the helping behaviour it motivates in erratic, inefficient, and irrational directions (25). For compassion to play a fundamental role in ethics of care, a specific relation between emotion and reason on the one hand and the relation to other persons on the other (1) is required. As I have argued with reference to trust, affect gives meaning to rational considerations about objective measures concerning incentives underpinning health system or quality of care thus enabling the systemic trust (22). Thus, we place an expectation in (unknown) doctors to display compassion because of our shared humanity (identification based trust). But we also rely on their professional duty of care and non-malfeasance as well as the knowledge that they have no incentives to act otherwise in publicly funded system that institutional trust in the abstract capacities of the system bolsters. Policies and organisational structures reinforcing or destroying systemic and/or interpersonal trust can have a very similar effect on compassion in healthcare.

The widely discussed Francis Report (4), identifying 'the need to change a culture focused on doing the system's business - not that of patients' (p. 4) is a key lesson from Staffordshire hospital's tragic neglect of patients care in another such example. The Mid Staffordshire NHS Trust failures in rudimentary aspects of care and the widespread and systemic patient abuse taking place in the hospital [involving leaving dying patients hungry, soiled and in pain for hours see (5)] is extreme but not unusual. It was shown to be a direct result of giving priority to demonstrating 'financial health' by the hospital. As the hospital's management embarked on cutting costs in this specific case, the staffing requirements needed to provide adequate patient care, and arguably the patients themselves, were ultimately seen as 'getting in the way' of achieving the hospital's strategic goal. The Francis Report provides a damning indictment of such an approach: 'While the system as a whole appeared to pay lip service to the need not to compromise services and their quality, it is remarkable how little attention was paid to the potential impact of proposed savings on quality and safety' (4) (p. 45). Nurses were working 12-hour shifts and were often replaced by less qualified assistants in order to decrease costs (3).

But how could managers or even the frontline staff distance themselves from the obvious task of providing care to the point of criminal negligence? Though moral responsibility for any action rests ultimately with the individual, the widespread failing in care standards cannot be simply attributed to callous and uncaring staff. Recent research suggests how almost anyone might engage in unethical behaviour, thanks to a complicated and socially reinforced mix of organisational and individual factors having to do with mental framing, perceptions and unconscious motives (26). Furthermore, organisational theory indicates that when explicit targets are coupled with strong incentives (and/or disincentives), individuals will often strive to meet them at the expense of a common sense (27). This could sometimes even lead to them violating socially accepted norms (28) as they are working towards meeting impersonal organisational targets (29). However, compassion can be cultivated through training that increases altruistic behaviour in compassion trainees via neural mechanisms controlling emotion prompting them to respond to rather than avoid suffering of others (30).

The proposal to incentivise compassion proposed by the UK government to address the failures of care (3) will not succeed if it is not geared to promote prosocial behaviour but rather to implement target measures that have induced the failure of compassion in the first place. It might also impose a whole new set of burdens on the health services (11) if health professionals are required to meet newly 
proposed compassion targets with resources being further diverted towards the management, measurement and monitoring of compassion. The issue therefore is not the absence of compassion by doctors and nurses per se but how organisational cultures, policies and politics might exert a damaging influence on caring values (2). Shift towards impersonal surveillance systems coupled with cost savings measures imposed by those who are distanced from the reality of care militates against developing compassionate caring institutions. Put differently, codes of ethics along with the lengthy socialisation process into the norms and values of the profession might be difficult to adhere to when resources are squeezed and norms and values are altered. Policies must reflect this reality to avoid undesirable consequences of the lack of compassion in health services that is antithetical to the idea of care.

\section{Conclusion}

Providing adequate training to healthcare professionals proposed by the UK government to remedy poor care and neglect may be an effective way of ensuring that nurses and doctors treat their patients with compassion only if it is followed by specific measures and policies that will nurture and develop such attitudes. Managers and organisations are critical to the creation of an ethical environment but the overall policy framework in which they operate is even more important. Recognising the importance of compassion as an inherent aspect of care does not only require explicit incorporation of ethical training as part of health education (1). Painstaking and systematic implementation of relevant policies in the context of institutional healthcare settings is essential for embedding and cultivating compassionate attitudes in health professionals.

\section{Acknowledgments}

I would like to thank two anonymous for their very useful comments and references which helped me to rethink and improve this editorial. All remaining errors are mine alone.

\section{Ethical issues}

Not applicable.

\section{Competing interests}

Author declares that she has no competing interests.

Author's contribution

MF is the single author of the manuscript.

\section{References}

1. Leget $\mathrm{C}$, Olthuis $\mathrm{G}$. Compassion as a basis for ethics in medical education. J Med Ethics 2007; 33, 617-20. doi: 10.1136/ jme.2006.017772

2. Flynn M, Mercer D. Is compassion possible in a market-led NHS? Nursing Times 2013; 109: 12-4.

3. Fotaki M. On compassion, markets and ethics of care. Centre for Health and the Public Interest; 2013. Available from: http://chpi. org.uk/on-compassion-markets-and-ethics-of-care/

4. Francis R. Report of the Mid Staffordshire NHS Foundation Trust Public Inquiry (ed). The Mid Staffordshire NHS Foundation Trust Public Inquiry. London; 2013.

5. Donnelly L. Stafford Hospital: the scandal that shamed the NHS [internet]. 6th January, 2013. Available from: http://www. telegraph.co.uk/health/heal-our-hospitals/9782562/StaffordHospital-the-scandal-that-shamed-the-NHS.html

6. Cole-King A, Gilbert P. Compassionate care: The theory and the reality. Journal of Holistic Health Care 2011; 8: 29-37.

7. Gilbert P, Choden K. Mindful Compassion: Using the Power of Mindfulness and Compassion to Transform Our Lives. London: Constable-Robinson; 2013.

8. Gilbert P. Compassion Focused Therapy: The CBT Distinctive Features Series. London: Routledge; 2010.

9. Brown B, Crawford P, Gilbert P, Gilbert J, Gale G. Practical compassion: Repertoires of practice and compassion talk in acute mental healthcare. Sociol Health IIIn 2014; 36: 383-99. doi: 10.1111/1467-9566.12065

10. Tronto JC. Creating caring institutions: Politics, plurality, and purpose. Ethics and Social Welfare 2010; 4: 158-71.

11. Smajdor A. Compassion is not the answer to failings in the NHS. The Guardian [internet]. 19th September 2013. Available from: http://www.theguardian.com/healthcare-network/2013/sep/19/ compassion-failings-nhs

12. Halpern J. From a Detached Concern to Empathy. Humanizing Medical Practice. Oxford: OUP; 2001.

13. Matthews DA, Suchman AI, Branch WT. Making 'connexions': Enhancing the therapeutic potential of patient-clinician relationship. Ann Intern Med 1993; 118: 973-7. doi: 10.7326/00034819-118-12-199306150-00010

14. White M. Kantian Ethics and Economics: Autonomy, Dignity, and Character. Berkeley: Stanford University Press; 2011.

15. Ross KL. Immanuel Kant (1724-1804). 2008. Available from: http://www.friesian.com/Kant.htm\#note-1

16. Schopenhauer A. The Basis of Morality (trans. E.F.J. Payne). New York: Bobbs-Merrill; 1995.

17. Solomon R. The moral psychology of business: care and compassion in the corporation. Bus Ethics Q 1998; 8: 515-33. doi: $10.2307 / 3857435$

18. Andre J. Learning to see: moral growth during medical training. $J$ Med Ethics 1992; 18: 148-52.

19. Noddings N. Caring. Los Angeles: University of California Press; 1984.

20. Gilligan C. In A Different Voice. Cambridge: Harvard University Press; 1982.

21. Butler J. Giving An Account of Oneself. New York: Fordham University Press; 2005.

22. Fotaki M. Can consumer choice replace trust in the National Health Service in England? Towards developing an affective psychosocial conception of trust in health care. Sociol Health IIIn 2014; 36: 1276-94. doi: 10.1111/1467-9566.12170

23. Berlant L. Compassion: The Culture and Politics of an Emotion. London and New York: Routledge; 2004.

24. Poppke J. Geography and ethics: everyday mediations through care and consumption. Prog Hum Geogr 2006; 30: 504-12. doi: 10.1191/0309132506ph622pr

25. Guyett GH, Haynes B, Jaeschke RZ, Cook DJ, Green L, Naylor CD, et al. Users' guide to the medical literature: XXV. Evidence-based medicine: principles for applying the users' guides to patient care. JAMA 2000; 284: 1290-6. doi: 10.1001/ jama.284.10.1290

26. Bazerman M, Banaji M. The social psychology of ordinary ethical failures. Soc Justice Res 2004; 17: 111-5. doi: 10.1023/b:so re.0000027544.56030.04

27. Schwartz H. Anti-social actions of committed organizational participants: An existential psychoanalytic perspective. Organization Studies 1987; 8: 327-40. doi: 10.1177/017084068700800403

28. Fotaki M, Hyde P. Organizational blind spots: Splitting, blame and idealization in the National Health Service. Hum Relat 2014; 68: 441-62. doi: 10.1177/0018726714530012

29. Ferlie E, McGivern G, FitzGerald L. A new mode of organizing in health care? Governmentality and managed networks in cancer services in England. Soc Sci Med 2012; 74: 340-7. doi: 10.1016/j.socscimed.2011.03.021

30. Weng HY, Fox AS, Shackman AJ, Stodola DE, Caldwell JZ, Olson MC, et al. Compassion training alters altruism and neural responses to suffering. Psychol Sci 2013; 24: 1171-80. doi: 10.1177/0956797612469537 